\title{
Chemical and structural effects of phosphorus on the corrosion behavior of ion beam mixed $\mathrm{Fe}-\mathrm{Cr}-\mathrm{P}$ alloys
}

\author{
J. D. Demaree and G. S. Was

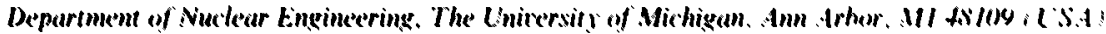 \\ N. R. Sorensen

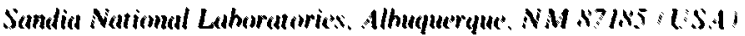

\begin{abstract}
An experimental program was conducted to determine the mechanisms by which phosphorus affects the corresion and passivation behavior of le Cr P alloys. To identify separately the effects of structure and chemistry on the corrosion behavior. thin films of 10--10Cr $\times P(0 \leq x \leq 35$ at. $\%)$ were prepared by ion beam mixing. Films with a phosphorus content greater than approximately 20 at. \% were found to be entirely amorphous. Devitritication of the amorphous phase was accomplished by heating the samples to 450 C in an inert environment.

Standard polarization tests of the alloys in sulfuric acid (with and without (l) lindicated that the lilms containing phosphorus were more corrosion resistant than Fe $10 \mathrm{Cr}$, at both active and passive potentials. There was a monotonic relationship between the amount of phosphorus in the alloy and the corrosion resistance, with the open-circuit corrosion rate of Fe l(KCr.35P nearly four orders of magnitude lower than that of Fe $10 \mathrm{Cr}$. Devitrilication of the alloys had no significant effect on the courrosion rate. indicating that the primary effect of phosphorus is chemical in nature, and ont structural. The passive oxides were depth-profiled using $X$-ray photoelectron spectroscopy. which indicated that phosphorus was a primary constituent, as phosphate. The presence of phosphate in the passive oxides reduced the overall corrosion rate directly, by suppressing anodic dissolution. The presence of phosphorus did enhance chromium enrichment in the oxide, but that was not thought to be the primary mechanism by which phosphorus increased the corrosion resistance.
\end{abstract}

\section{Iatroduction}

Amorphous metals, alloys with no long-range crystal structure, often exhibit unusual resistance to degradation in corrosive aqueous environments. The remarkable aqueous corrosion resistance of amorphous alloys was first noted by Hashimoto and coworkers in the early 1970 s [1]. Since then, many researchers have investigated this phenomenon in a variety of glassy alloys, considering both metal-metal and metal-metalloid systems [2 20]. The primary mechanism by which these alloys remain passive in highly corrosive environments is a matter of controversy. The mechanisms commonly proposed to explain this phenomenon may be categorized as chemical or structural in nature. Structural mechanisms emphasize the single amorphous phase and chemical homogeneity of most metallic glasses, which are intrinsic benefits of the amorphous structure. These alloys lack the surface inhomogeneities which usually act as primary corrosion sites. leading to accelerated corrosion at crystalline imperfections such as grain boundaries and secondphase particles. Proposed chemical mechanisms emphasize the presence of large amounts of metalloid in metal metalloid glasses. Most techniques used to produce metallic glasses require around 20 at. $\%$ of a metalloid (boron, phosphorus, silicon or carbon) to be added to the metal [21], which can alter the primary chemical reactions occurring at the surface during aqueous corrosion. In this study, ion beam mixing was used to fabricate amorphous $\mathrm{Fe} 10 \mathrm{Cr}$ xP alloy films $(0<x<35$ at.\%). and the corrosion behavior in acid solutions was studied to determine whether the high corrosion resistance of these alloys is primarily a result of the non-metallic surface chemistry or an intrinsic benefit of the amorphous structure.

\section{Experimental procedure}

Fe-10Cr-x films were prepared by ion beam mixing 18 alternating layers of $\mathrm{Fe} / \mathrm{FeP} / \mathrm{Cr}$. produced by sequential electron-gun evaporation of iron, chromium, and $\mathrm{Fe}_{3} \mathrm{P}$ sources in a vacuum evaporator (base vacuum $5 \times 10^{8}$ Torr), with a total thickness of $60 \mathrm{~nm}$ and phosphorus concentrations of $0,8,15,25$ and 35 at. $\%$ (adjusted by varying the iron-to-FeP thickness ratio). These films were evaporated onto glass microscope slides and freshly cleaved $\mathrm{NaCl}$ crystals. The films were irradi- 
ated with $300 \mathrm{keV} \mathrm{Kr}^{+}$ions in a Varian 400 ion implanter, to a total dose of $1 \times 10^{16}$ ions $\mathrm{cm}^{-2}$. The samples were cooled to a temperature of approximately $-100^{\circ} \mathrm{C}$ during irradiation to prevent the formation of equilibrium phases. Samples of each film composition were heat treated at $450^{\circ} \mathrm{C}$ for $2 \mathrm{~h}$ in an argon flow furnace to devitrify the amorphous phase.

The films were characterized by $2 \mathrm{MeV} \mathrm{He}{ }^{+}$Rutherford backscattering spectrometry (RBS), using a General Ionex Tandetron accelerator, to be certain that the films were chemically homogeneous throughout their thickness. The films on $\mathrm{NaCl}$ crystals were floated off in distilled water onto copper transmission electron microscopy grids, and examined in a JEOL 2000FX analytical electron microscope to examine the microstructure.

The corrosion behavior of the films deposited onto glass slides and $\mathrm{Fe}-10 \mathrm{Cr}$ was examined in $0.1 \mathrm{~N}$ sulfuric acid, with and without $500 \mathrm{ppm} \mathrm{Cl}^{-}$. All solutions were prepared with deionized water and were not deaerated. Most potentiodynamic scans were performed at a rate of $1 \mathrm{mV} \mathrm{s}^{-1}$, beginning at a potential at least $250 \mathrm{mV}$ below the open-circuit potential. The open-circuit corrosion rate $I_{\text {corr }}$ was measured using polarization resistance measurements [22], scanning the applied potential at a rate of $0.3 \mathrm{mV} \mathrm{s}^{-1}$ near the open-circuit potential. Potentiostatic current decay curves were obtained by stepping the potential from open-circuit to $+500 \mathrm{mV}$ (vs. a saturated calomel electrode, SCE) and measuring the anodic current through the sample.

Following ion beam mixing, heat treatment, and potentiostatic polarization, the passive oxides were examined by X-ray photoelectron spectroscopy (XPS) using a PHI 5400 system ( $300 \mathrm{~W}, 15 \mathrm{kV}$ magnesium). An argon ion beam was used to depth profile the surface oxide and some of the underlying metallic film. The sputter rate was approximately $0.3 \mathrm{~nm} \mathrm{~min}$ min $^{-1}$ in the metallic film, as measured by completely sputtering through a film of known thickness. Since oxides generally have $20 \%-30 \%$ of the sputter yield of metals, it is assumed that the sputter rate in the oxide portion of the profiles was roughly $0.1 \mathrm{~nm} \mathrm{~min}{ }^{-1}$. Standard sensitivity factors were used to convert photoelectron peak heights to elemental composition.

\section{Experimented results}

RBS analysis showed that the ion dose used for mixing was sufficient to homogenize completely the evaporated layers. The ion beam irradiation also provided the stimulus for the crystalline to amorphous phase transition in samples with sufficient phosphorus to stabilize that phase. Figure 1 shows bright field electron micrographs of the five alloys studied, along with their selected area electron diffraction patterns, immediately after irra- diation. Both the $\mathrm{Fe}-10 \mathrm{Cr}$ and the $\mathrm{Fe}-10 \mathrm{Cr}-8 \mathrm{P}$ alloys appeared to be entirely crystalline, as no evidence of an amorphous halo could be found in the electron diffraction pattern. The Fe-10Cr-15P alloy consisted of both the b.c.c. phase and an amorphous phase. Both the $\mathrm{Fe}-10 \mathrm{Cr}-25 \mathrm{P}$ and $\mathrm{Fe}-10 \mathrm{Cr}-35 \mathrm{P}$ alloys were entirely amorphous, although the electron diffraction halo in the $\mathrm{Fe}-10 \mathrm{Cr}-25 \mathrm{P}$ alloy seemed slightly sharper than that of the higher phosphorus alloy. Figure 2 shows the same alloys after heat treatment at $450^{\circ} \mathrm{C}$ for $2 \mathrm{~h}$. The alloys which contained phosphorus showed evidence of $\mathrm{Fe}_{2} \mathrm{P}$ after heat treatment. After heat treatment, the $\mathrm{Fe}-10 \mathrm{Cr}-8 \mathrm{P}$ and $\mathrm{Fe}-10 \mathrm{Cr}-15 \mathrm{P}$ alloys consisted of both b.c.c. iron-chromium and $\mathrm{Fe}_{2} \mathrm{P}$, while the devitrified $\mathrm{Fe}-10 \mathrm{Cr}-25 \mathrm{P}$ and $\mathrm{Fe}-10 \mathrm{Cr}-35 \mathrm{P}$ alloys consisted almost entirely of $\mathrm{Fe}_{2} P$, with only a few diffaction spots corresponding to the b.c.c. phase. Because of the complexity of the diffraction patterns, and coincident plane spacings, it was not possible to determine whether $\mathrm{Fe}_{3} P$ was present in the devitrified alloys.

Potentiodynamic polarization data for the ion beam mixed alloys in $0.1 \mathrm{~N}$ sulfuric acid are shown in Fig. 3. The presence of phosphorus has a strong effect on the anodic current density of the samples, reducing the passive current density by more than two orders of magnitude and eliminating the prominent active peak altogether. The ion beam mixed $\mathrm{Fe}-10 \mathrm{Cr}$ alloy on a glass substrate dissolved so rapidly that it was impossible to record a potentiodynamic scan, even at $10 \mathrm{mV} \mathrm{s}^{-1}$ (the curve shown for Fe-10Cr in Fig. 3 is that of the $\mathrm{Fe}-10 \mathrm{Cr}$ evaporated film on a polished $\mathrm{Fe}-10 \mathrm{Cr}$ substrate - all of the other data are from alloys on glass substrates). It should be noted that the cathodic portion of the scans seems relatively unaffected by the presence of phosphorus. The addition of $500 \mathrm{ppm} \mathrm{Cl}^{-}$to the solution led to pitting in the $\mathrm{Fe}-10 \mathrm{Cr}$ alloy, but did not induce pitting in the phosphorus alloys.

The open-circuit corrosion rate $I_{\text {corr }}$ of the alloys exhibited a monotonic relationship with the amount of phosphorus in the alloys (Fig. 4). $I_{\text {corr }}$ of the $\mathrm{Fe}-10 \mathrm{Cr}-35 \mathrm{P}$ alloy was over four orders of magnitude lower than that of the base alloy. The corrosion rate was not significantly affected by heat treatment, even when the heat treatment devitrified the amorphous alloys.

Potentiostatic current decay measurements are shown in Fig. 5, both on a very short time scale and over the entire hour of polarization. As in Fig. 3, it was necessary to use a bulk sample of $\mathrm{Fe}-10 \mathrm{Cr}$, as the evaporated film was removed from the substrate within seconds of polarization. The presence of phosphorus lowered both the peak current density immediately upon polarization and the passive current density $I_{\text {pess }}$ after $1 \mathrm{~h}$ by a factor of 20. A summary of the electrochemical data is presented in Table 1. 

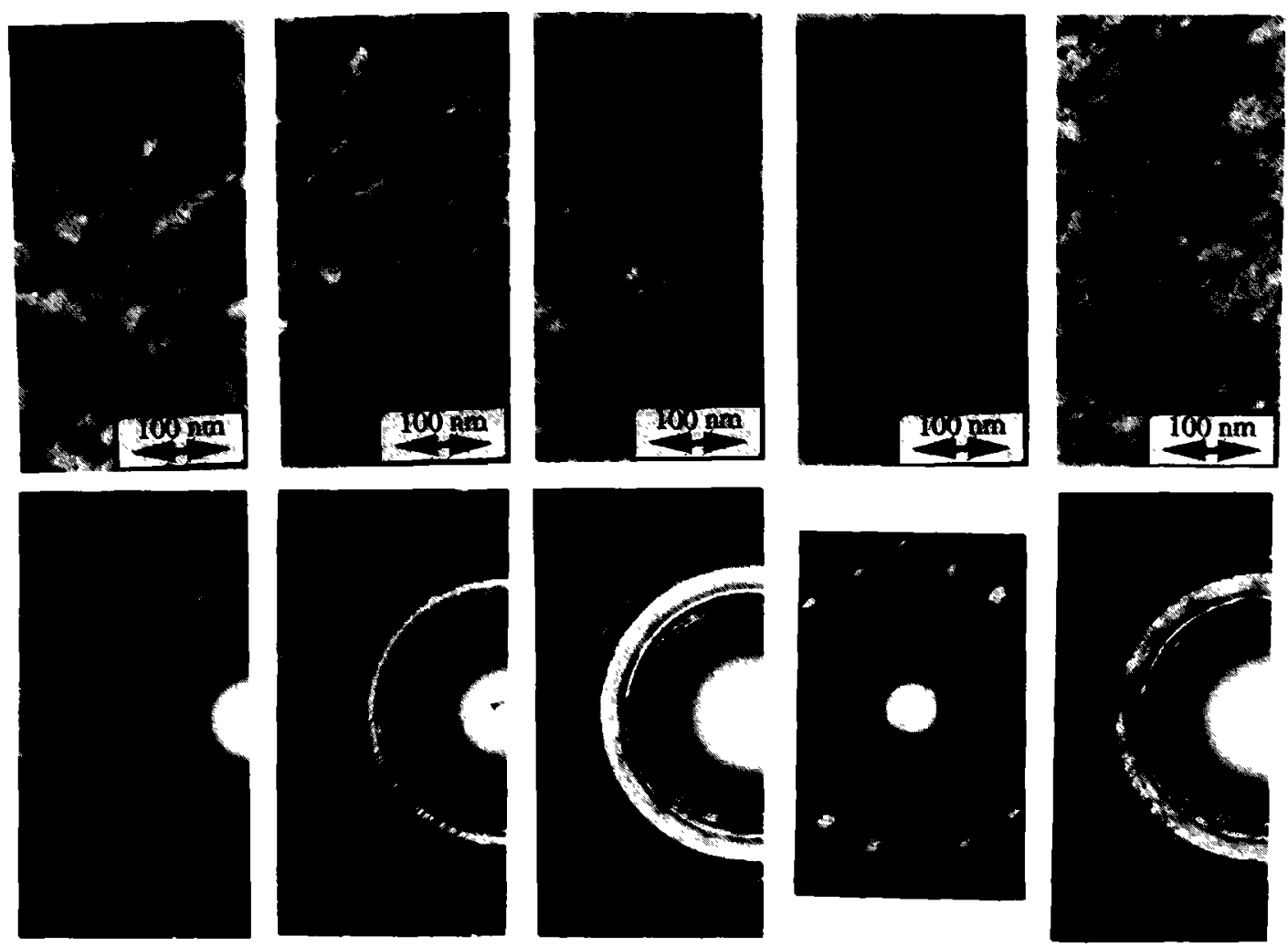

Fig. 1. Bright field electron micrographs and selected area electron diffraction palterns of ion boam mixed alloys.

The passive oxides on the ion beam mixed alloys were profiled with XPS after the $1 \mathrm{~h}$ polarization, and the results are plotted schematically in Fig. 6 (the Fe $10 \mathrm{Cr}$ alloy was studied after a $5 \mathrm{~s}$ polarization, before complete removal from the glass substrate). The oxides were approximately $0.5-1.5 \mathrm{~nm}$ thick, and consisted of oxidized iron, oxidized chromium, and phosphorus in a phosphate (pentavalent) state. The phosphorus alloys had passive oxides that were significantly more enriched in chromium than the base alloy, but the $[\mathrm{Cr}] /[\mathrm{Fe}]$ ratio of the phosphorus alloys was substantially the same from $15 \%$ phosphorus to $35 \%$ phosphorus. Phosphate was the primary constituent of the passive films on the $\mathrm{Fe} 10 \mathrm{Cr}-25 \mathrm{P}$ and $\mathrm{Fe}-10 \mathrm{Cr}-35 \mathrm{P}$ alloys, with $\mathrm{P}^{5+}$ comprising over $50 \%$ of the oxide cations.

\section{Discussion of results}

These results strongly suggest that the primary mechanism by which amorphous $\mathrm{Fe}-10 \mathrm{Cr}$ - P alloys resist corrosion is chemical in nature, and not structural. It is asserted that the corrosion resistance of these alloys depends primarily on the amount of phosphorus present in the alloy, and does not depend on the presence of the amorphous phase. First. the addition of only $8 \mathrm{at} . \%$ phosphorus lowered both $I_{\text {corr }}$ and $I_{\text {pus }}$ significantly. without producing a change in the alloy microstructure. indicating that phosphorus can suppress anodic dissolution merely by its chemical presence. Second, the increase in phosphorus concentration from 25 to 35 at. \% lowered the corrosion rate significantly, again without inducing a phase transformation (both alloys were entirely amorphous). Third. both $I_{\text {pas }}$ and $I_{\text {surr }}$ were smooth functions of phosphorus concentration. and showed no anomalous decrease in corrosion rate coincident with the formation of the amorphous phase (15-25 at. \% phosphorus). Finally the crystallization of the amorphous alloys by heat treatment had no effect on the corrosion rates. The corrosion resistance of these alloys is primarily a function of phosphorus chemistry, and is not related to the presence of an amorphous phase.

The absence of degradation upon devitrifying the amorphous alloys was a surprising result. for it seemed to contradict earlier studies $[2,18,20,23,24]$. However, all previous studies of this nature have used alloys which crystallized into more heterogeneous microstructures (e.g. b.c.c. iron, phosphides, and carbides). Ion beam mixing allowed the synthesis of amorphous $\mathrm{Fe}-10 \mathrm{Cr}-\mathrm{P}$ alloys without any other metalloid, something not pos- 

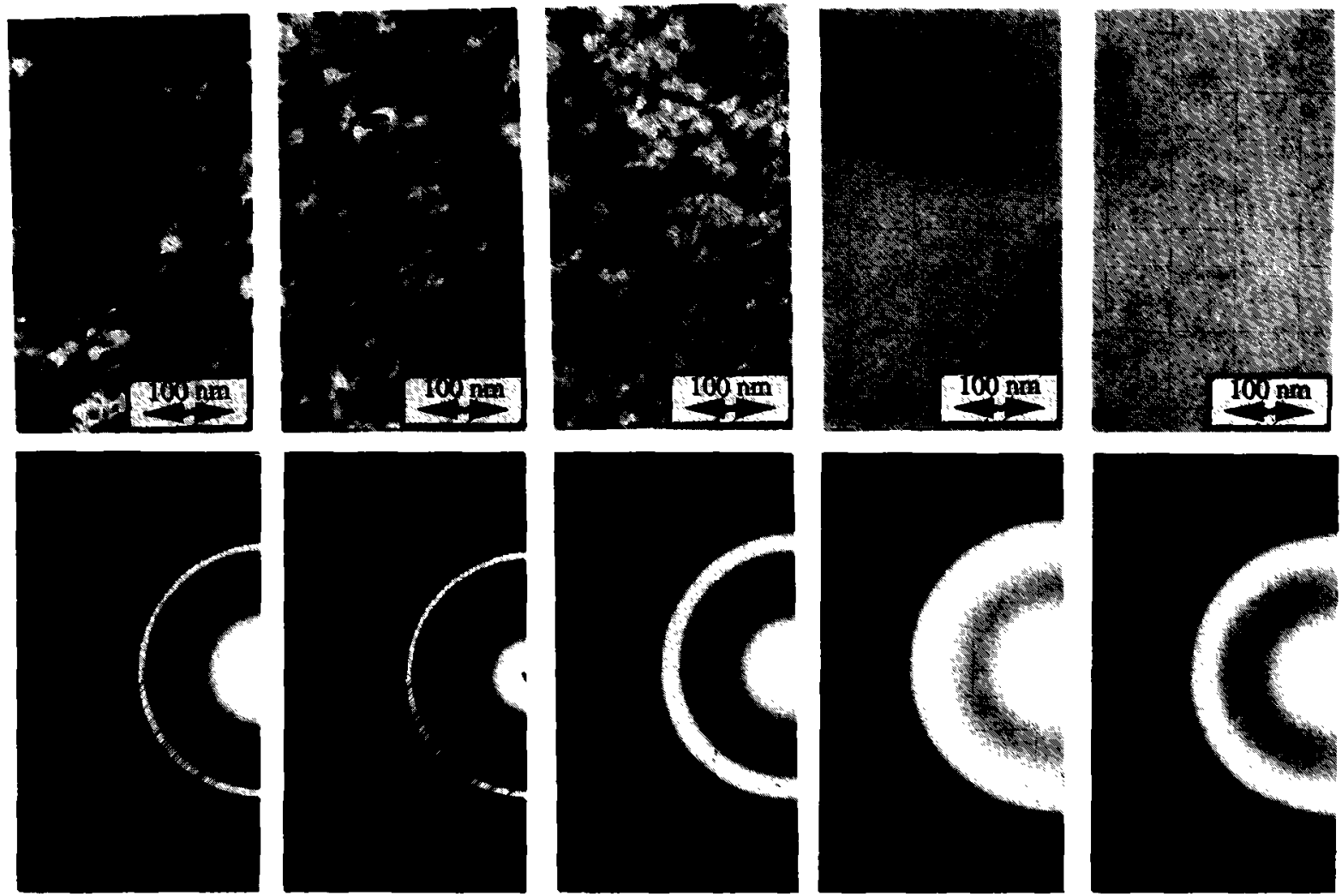

Fig. 2. Bright field electron micrographs and selected area electron diffraction patterns of alloys after heat treatment at $450^{\circ} \mathrm{C}$ for $2 \mathrm{~h}$.

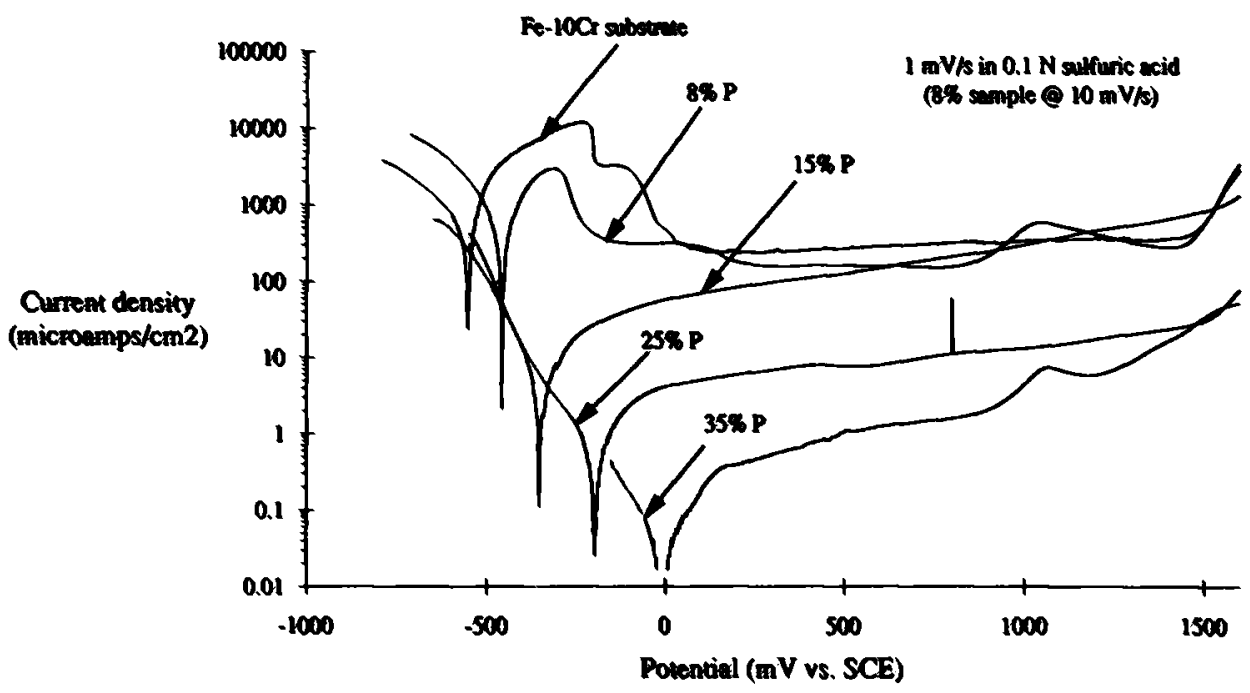

Fig. 3. Potentiodynamic polarization curves of ion beam mixed $\mathrm{Fe}-10 \mathrm{Cr}-\mathrm{P}$ alloys in $0.1 \mathrm{~N}$ sulfuric acid.

sible with rapid quenching techniques [13], and it is possible that the alloys in this study were essentially more homogeneous after devitrification than the alloys in previous studies. After devitrification, the alloys in this study consisted primarily of a single phase, $\mathrm{Fe}_{2} \mathrm{P}$, and any amounts of b.c.c. iron-chromium imbedded in the phosphide matrix in the $\mathrm{Fe}-10 \mathrm{Cr}-15 \mathrm{P}$ and
$\mathrm{Fe}-10 \mathrm{Cr}-25 \mathrm{P}$ alloys might have been rapidly removed from the surface almost immediately upon immersion into the electrolyte, as has been proposed in other systems [25].

XPS analysis indicated that the highly protective passive oxides formed on the high-phosphorus alloys differed from the less-protective passive oxides on the base alloy 
TABLE 1, Flectrochemical parameters of ion beam mixed allows

\begin{tabular}{|c|c|c|c|c|}
\hline at. $*$ P & $\begin{array}{l}\text { Current maximum } \\
\text { following potential } \\
\text { step to }+500 \mathrm{mV}_{\mathrm{sC}} \\
(\mu \mathrm{A} \mathrm{cm}-2)\end{array}$ & $\begin{array}{l}I_{\text {pars }} \text { (after } 1 \mathrm{~h} \\
\text { of passivation at } \\
\left.+500 \mathrm{mV}_{\mathrm{sct}}\right) \\
(\mu \mathrm{Acm} " 2)\end{array}$ & $\begin{array}{l}\text { Approximate open-circuit } \\
\text { potential from } \\
\text { potentiodynamic } \\
\text { tests ( } \mathrm{m}_{\text {SCE }} \text { ) }\end{array}$ & $\begin{array}{l}I_{\text {corr }} \\
\left(\mu A \mathrm{~cm}^{-2}\right)\end{array}$ \\
\hline 0 & 46000 & $45.5^{\circ}$ & -550 & 511 \\
\hline 8 & 21900 & 15.3 & -450 & 225 \\
\hline 15 & 34100 & 9.14 & -400 & 5.57 \\
\hline
\end{tabular}

"Bulk sample of Fe-10Cr.

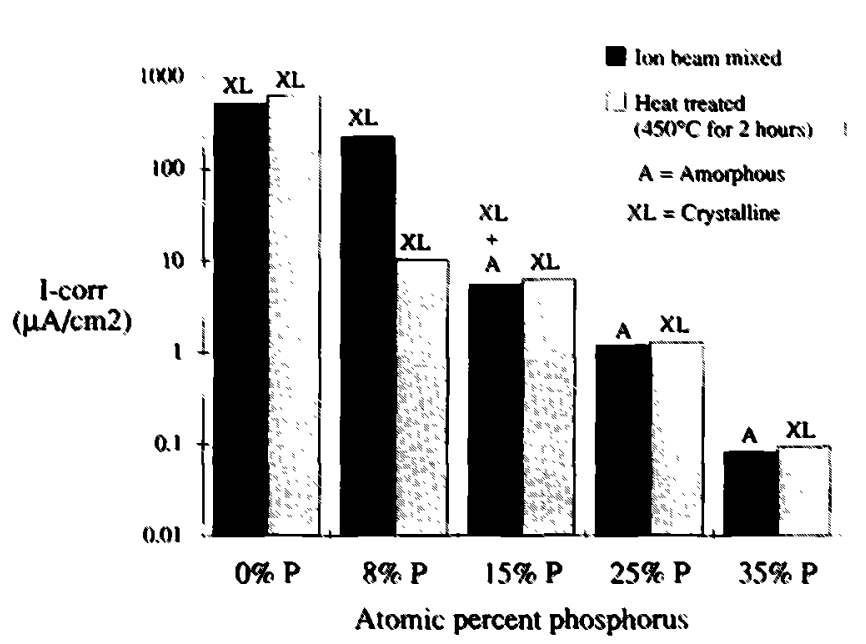

Fig. 4. Open-circuit corrosion rate $I_{\text {surr }}$ of ion beam mixed fe 10Cr. P alloys in $0.1 \mathrm{~N}$ sulfuric acid before and after heat treatment at $450 \mathrm{C}$ for $2 \mathrm{~h}$, as measured by polarization resistance tests.

in at least two ways: phosphate composition and chromium enrichment. XPS profiling revealed the development of a phosphate in the passive oxide on the phosphorus alloys, which may explain the increased corrosion resistance. It is possible that the phosphate complexes in the passive oxide act to suppress the inward diffusion of anionic complexes from the solution during aqueous corrosion. The phosphate film would shield the underlying alloy from the solution, and prevent the hydration of the underlying metal and subsequent anodic dissolution. In another commonly held model for the corrosion resistance of amorphous alloys, the preferential dissolution model [3], phosphorus is a catalyst to stimulate anodic dissolution and speed the accumulation of film-forming elements at the alloy surface, accelerating the formation of a chromium-rich oxide. The $[\mathrm{Cr}] /[\mathrm{Fe}]$ ratio of the passive oxides on the phosphorus alloys was 5-10 times greater than that of the base alloy, but showed no clear correlation with the corrosion rate as the phosphorus content increased from 8 to 35 at.\%. On the contrary, the presence of phosphorus decreased the initial anodic dissolution rate (Fig. 5), rather than stimulating it, as would be expected by the preferential dissolution
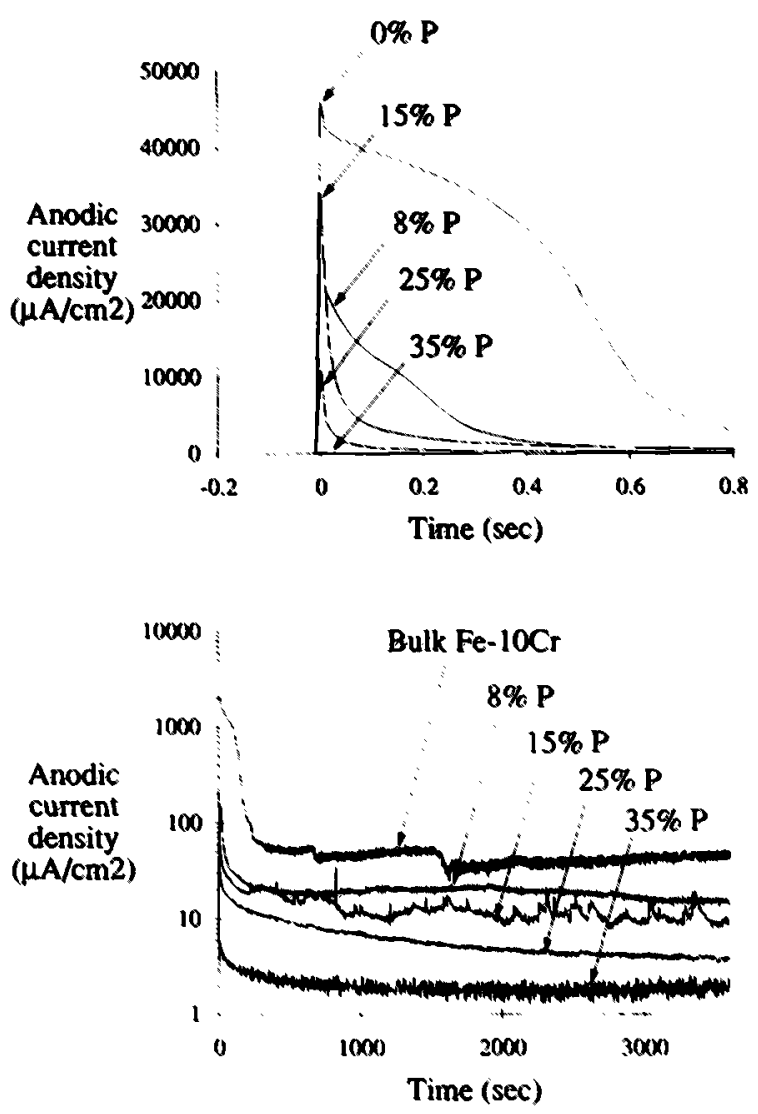

Fig. 5. Potentiostatic current decay behavior of ion heam mixed Fe $10 \mathrm{Cr}$. P alloys stepped to $+500 \mathrm{mV}_{\text {ser }}$. at both short and long time scales. in $0.1 \mathrm{~N}$ sulfuric acid.

model. Although this model may explain the increased corrosion resistance of the $\mathrm{Fe} 10 \mathrm{Cr} 8 \mathrm{P}$ alloy relative to the base alloy, it does not explain the further increase in corrosion resistance as more phosphorus is added.

\section{Summary}

(1) Ion beam mixing techniques can be successfully employed to produce chemically homogeneous thin films of $\mathrm{Fe}-10 \mathrm{Cr}-\mathrm{P}$, with phosphorus compositions from 0 to 35 at.\%. Thin films prepared in this way will be 

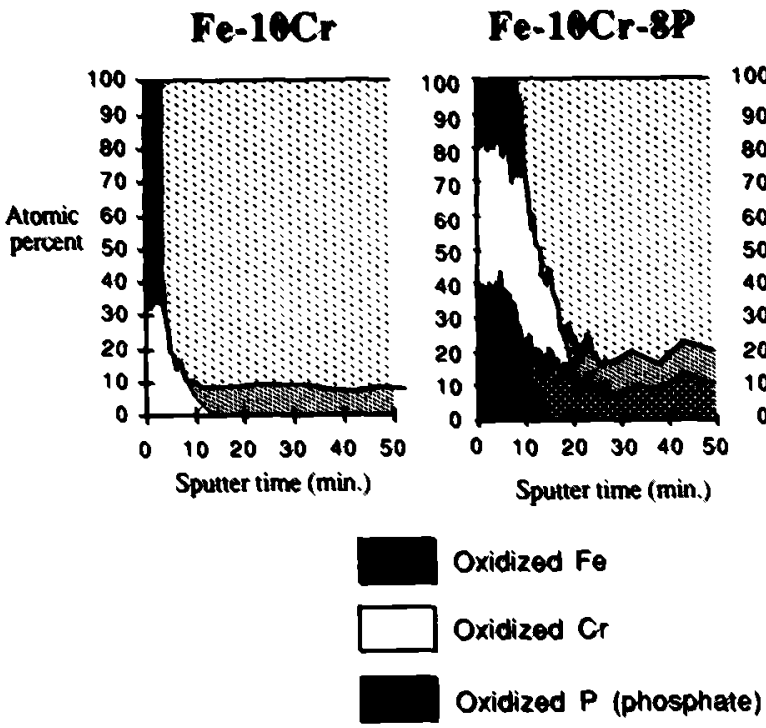
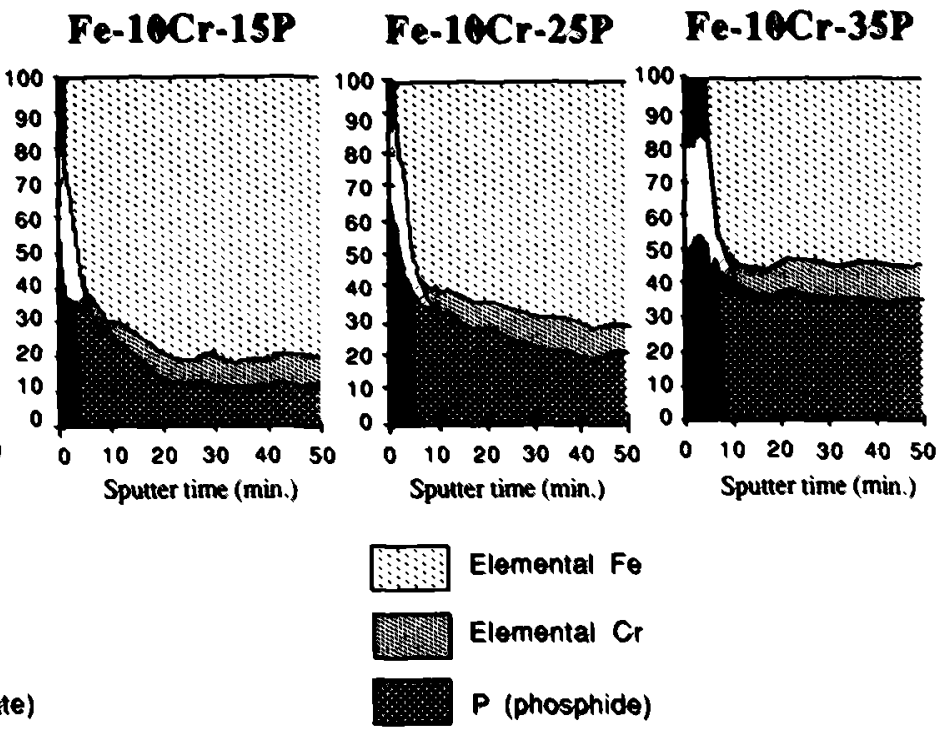

Fig. 6. XPS depth profiles of passive oxides on ion beam mixed Fe-10Cr-P alloys after polarization at $+500 \mathrm{mV}$ sce for $5 \mathrm{~s}$ (Fe-10Cr alloy) and for $1 \mathrm{~h}$ (all other alloys) in $0.1 \mathrm{~N}$ sulfuric acid.

amorphous if a sufficient amount of phosphorus is present. Films with 15\% phosphorus consisted of amorphous and crystalline phases. Films with $25 \%$ and $35 \%$ phosphorus were entirely amorphous.

(2) The presence of phosphorus reduced the active and passive current densities significantly, with the size of the reduction increasing with the amount of phosphorus. The corrosion resistance of these alloys is chemically controlled, and is not a result of the amorphous phase. Additions of phosphorus to both crystalline and amorphous alloys lowered the corrosion rate without any apparent change in crystal structure. Devitrification of the amorphous alloys had no effect on the corrosion behavior.

(3) Phosphorus, in the form of phosphate, was a major constituent of the oxides formed on the films containing large amounts of phosphorus. This phosphate may provide a barrier against anodic dissolution, and be the primary factor in the corrosion resistance of the high phosphorus alloys. The presence of phosphorus enhanced the amount of chromium present in the passive oxide, but the preferential dissolution model could not explain the results of this study.

\section{Acknowledgnents}

Thin film synthesis and ion irradiation experiments were performed at the Michigan Ion Beam Laboratory for Surface Modification and Analysis. Electron microscopy and XPS analysis was performed at the University of Michigan's North Campus Electron Microbeam Analysis Laboratory, and electrochemical tests were performed at the University of Michigan's High Temper- ature Corrosion Laboratory. The authors would like to acknowledge gratefully the assistance of Sandia National Laboratories.

\section{References}

1 M. Naka, K. Hashimoto and T. Masumoto, Jpn. Inst. Met., 38 (1974) 835.

2 M. Naka, K. Hashimoto and T. Masumoto, Corrosion, 32 (4) (1976) 146-152.

3 K. Hashimoto, K. Osada, T. Masumoto and S. Shimodaira, Corros. Sci. 16 (1976) 71-76.

4 M. Naka, K. Hashimoto and T. Masumoto, J. Non-Cryst. Solids. 28 (1978) 403-413.

5 M. Naka, K. Hashimoto and T. Masumoto, J. Non-Cryst. Solids. 31 (1979) 355-365.

6 K. Asami, K. Hashimoto, T. Masumoto and S. Shimodaira, Corros. Sci. 16 (1976) 909-914.

7 Y. Waseda and K. T. Aust, J. Mater. Sci. 16 (1981) 2337-2359.

8 C. R. Clayton, K. G. K. Doss, Y.F. Wang, J. B. Warren and G. K. Hubler, Proc. Conf. on Ion Implantation in Metals. Manchester. 1981, Pergamon, Oxford, 1982, pp. 67-76.

9 D. R. Baer and M. T. Thomas, J. Vac. Sci. Technol., 18 (3) (1981) $722-726$.

10 G. T. Burstein, Corrosion, 37 (10) (1981) 549-556.

11 R. B. Diegle, N. R. Sorensen, C. R. Clayton, M. A. Helfand and Y. C. Yu, J. Electrochem. Soc., 135 (5) (1988) 1085-1092.

12 M. A. Helfand, C. R. Clayton, R. B. Diegle and N. R. Sorensen in R. B. Diegle and K. Hashimoto (eds.), Corrosion. Electrochemistry and Catalysis of Metallic Glasses, The Electrochemical Society, Pennington, NJ, 1988, p. 104.

13 T. P. Moffat, W. F. Flanagan and B. D. Lichter, J. Electrochem. Soc. 135 (11) (1988) 2712-2719.

14 T. P. Moffat, W. F. Flanagan and B. D. Lichter, Corrosion, 43 (10) (1987) 589-593.

15 R. B. Diegle, J. Non-Cryst. Solids, 61-62 (1984) 601-612.

16 N. R. Sorensen, R. B. Diegle and S. T. Picraux, J. Mater. Res. I (6) (1986) 752-757. 
17 N. R. Sorensen. R. B. Dicgle and S. T. Picraux. Corrosion. 4. (1) $119871 \geq 7$.

Is M. Naka, K. Hashimoto and T. Masumoto, Corrosiem, in (12) $(1980) 6796 \times 6$

19 V.S. Raja, Kishore and S. Ranganathan, Corrosiom, 44 (5) (1488) 263. 270

$20 \mathrm{~S}$.J. Thorpe, B. Ramaswami and K. T. Aust. J. Electrochem. Sor., $135(9)(1988) 21622170$.
21 P. Haasen, Phys, Bull. it (1978) 12

22 D. M. Drazic in B. E. Connay, J. OM. Beck ris and R. L. White (eds.) Modern Aspects of Electrohemistry. No. 19. Plenum Pross. New York, 1989, pp. 69192.

23 H.S. Tong. Corrosion. $1 /(1) 119 \times 5$ ) 10 12.

it M. Naka, K. Asami. K. Hashimoso and T. Masumeso. Pros, the Im. Conf. on Titumium, 14,840 leited in ref. 23).

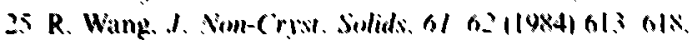

